\section{VISÕES DOS ESTUDANTES DE BIOLOGIA SOBRE QUESTÕES ÉTICAS ANIMAIS E AMBIENTAIS}

\author{
VISIONS OF BIOLOGY STUDENTS ON ANIMAL AND ENVIRONMENTAL ETHICAL ISSUES
}

\author{
Lucas Nascimento Ferreira Lopes \\ Carlos Ribeiro Martins Dimas
}

\begin{abstract}
Resumo: A Biologia é uma área vital para se discutir questões ambientais e animais na sociedade moderna, embora em sua graduação não se encontrem espaços para reflexão. Na pesquisa foram feitas entrevistas semiestruturadas com estudantes de graduação em Biologia para que pudessem falar abertamente sobre questões éticas que considerassem problemáticas dentro da sua formação em especial nas áreas das temáticas animal e ambiental. Seus discursos foram analisados seguindo a Perspectiva dos Funcionamentos para observar funcionamentos comprometidos e buscar formas de estimula-los. Ao fim podemos ver um número elevado de discussões suscitadas pelos alunos. Dentro da questão animal há a questão problemática da experimentação animal e uso didático de animais dentro da universidade. Já na questão ambiental sobressaem-se para os alunos a identidade do profissional biólogo fortemente relacionado a temática e o próprio conceito de preservar. Formas de se reconectar a Bioética e estimular espaços de reflexão são vitais para criar profissionais devidamente preparados pra lidar com as demandas atuais de ações do biólogo, tanto em conhecimento quanto em ética.
\end{abstract}

Palavras-Chave: Bioética. Biologia. Ética Ambiental. Ética Animal. Currículo de Biologia

\section{INTRODUÇÃO}

A discussão de questões ambientais salientou-se atualmente como um ponto constante em distintas esferas de debates, de políticas à socioeconômicas. Isso tem se dado muito por questão das consequências palpáveis de ações antropogênicas no ambiente afetando variadas formas de vida e com consequências diretas aos seres humanos. De fato, o grau irreversível e amplo de mudanças que muitas dessas ações têm feito sobre o próprio planeta são o suficiente para delimitar e caracterizar um novo período geológico, denominado Antropoceno (KOHLBERG, 2014).

Dentro desse panorama, diferentes áreas de conhecimento são envolvidas nos debates sobre a questão ambiental na atualidade. Dentre elas a Biologia, que tanto por seu histórico quanto pela sua diversidade, salienta-se como vital para essas discussões. Em sua diversidade a Biologia permite trazer

\footnotetext{
${ }^{1}$ Doutorando do curso de Bioética, Ética Aplicada e Saúde Coletiva do Programa de Pós-Graduação em Bioética, Ética Aplicada e Saúde Coletiva. E-mail: <lucas.lopes22@hotmail.com>

${ }^{2}$ Professor associado da Universidade Federal Fluminense. E-mail: <dimasmribeiro@gmail.com>
} 
conceitos de Ecologia, Etologia, Preservação Ambiental, Genética e outras divisões que contribuem com a expertise para se identificar e debater questões ambientais.

Com isso as atenções voltam-se para o profissional biólogo que atuará junto a sociedade. Um profissional diversificado, com atuações distintas desde o campo educacional (magistério e academia) até consultoria e trabalhos técnicos, o biólogo possui uma gama de variações e interações com as variadas formas de vida do planeta. Tal diversidade é reflexo da própria estruturação da área, com suas variadas especializações (SAPP, 2003).

É de se pensar então que devido a essa diversidade de atuações, em especial em áreas de sensível importância social, política e econômica, como a ambiental e animal, o biólogo teria uma formação tanto técnica e conteudista, quanto igualmente reflexiva fornecendo-o ferramentas para pensar sua atuação e posicionar-se eticamente. Entretanto isso não aparenta ser o caso.

De fato há uma significativa escassez na bibliografia internacional e nacional sobre o tema de Biologia e ética ou Biologia e Bioética. Essa última, uma área multidisciplinar da ética aplicada, engloba em si discussões de ética ambiental e ética animal, dois pontos essenciais ao se debater os impactos antropogênicos no planeta e formas de combate-los (PESSINI, 2013).

A Bioética, que surge inicialmente junto a uma forte preocupação com a degradação ambiental, verteu-se nos últimos anos para focar em questões de ética biomédica, da saúde humana e genética, em especial de vida e de morte (AZEVEDO, 2010). De forma geral poucos artigos foram produzidos sobre o tema de Bioética e Biologia, o que reforço a importância de explorar e debater mais o tema.

Estudos tais como o de Kolarova \& Denev (2012) na Bulgária e de Bryant \& LaVelle (2003) no Reino Unido demonstram práticas e tentivas pedagógicas de se inserir a Bioética na educação dos biólogos, incentivando professores a implementar esta disciplina em suas universidades. Esses trabalhos demonstram que a iniciativa de inserção da Bioética dentro da Biologia é ainda pouco recorrente, porém necessária.

A própria questão ambiental, mencionada anteriormente, é relegada. A ponte entre os conhecimentos técnico adquiridos e a reflexão sobre atitudes e mudanças de postura não é estimulada na formação atual, o que acaba comprometendo a ação do biólogo enquanto promotor de mudanças de paradgimas (CONRADO et al. 2013).

No Brasil há um vazio ainda maior sobre o tema. O estudo de Dória e Moreira (2015) mostra que o ensino de Bioética é pouco representado. O estudo analisa os currículos dos curso de Ciências Biológicas em Intuições de Ensino Superior Federais, tidas como referências nacionais de educação de qualidade, quanto à presença de disciplinas de Bioética ou de conteúdos similares. Das 50 instituições analisadas, apenas 36 ofereceram informações de disciplinas que ofertasse os conteúdos em questão e deste total, apenas 50\% possuíam disciplinas de Bioética ou similares. Analisando as ementas das 14 instituições que ofereciam tal disciplina, puderam observar que o conteúdo programático apresenta o mesmo enfoque observado nos trabalhos acadêmicos dessa área, voltados especialmente para questões biomédicas e de saúde humana, do que para questões ambientais e que incluíssem seres não humanos.

Dentro especialmente da área de Ética Animal, considerado extremamente valoroso e necessário para o biólogo, o estudo de Pinto (2016) demonstra que o panorama é de igual escassez. Tanto em insituições de ensino superior públicas quanto privadas há um significativo vazio quanto à inclusão de ensinos ou dinâmicas sobre a ética dentro da Biologia, demonstrando um panorama geral de estrutura curricular empobrecida nessa área importante.

Os poucos estudos que se propuseram a analizar a Bioética na formação do biólogo, a fizeram através de pesquisas quantitativas (questionários fechados) e qualitativas de grupos focais e entrevistas, mas que não envolveram os discentes de Biologia. Nesses últimos casos, as entrevistas foram voltadas para professores do curso de Biologia e licenciandos apenas (SILVA, 2011) e especialistas da área de Bioética (SIEBERT, 2015). O trabalho de Downey (1993) lida diretamente com os alunos, no caso de um curso de Zoologia, porém foi realizado somente através de um questionário fechado. 
O caso do estudo de Silva (2011) é especificamente importante, porque não somente foi o primeiro estudo sobre o tema dentro do Brasil, como também ao abordar licenciandos recém-formados pôde perceber que estes se consideram despreparados para abordar temas mais polêmicos, como educação sexual, aborto, drogas, que em geral aparecem dentro do conteúdo programátic da Biologia nas escolas. Tais temas são eticamente relevantes e frequentemente abordados dentro da Bioética, que como mencionado anteriormente, encontra pouco espaço dentro das formações academicas em Biologia.

O estudo de Lopes (2017) trouxe uma nova luz sobre a problemática das questões éticas dentro da formação dos biólogos. Através de entrevistas semi-estruturadas junto aos próprios estudantes de graduação em Biologia da UFRJ pode-se conhecer questões ético-morais dos alunos que vivenciaram dentro de sua vida acadêmica na graduação.

Através da adoção de entrevistas semi-estruturadas o estudo busca ressaltar a voz dos estudantes, de forma mais livre e dinâmica, para entender que tipo de angústias ético-morais têm percebido dentro de sua formação ou vivência acadêmica.

O presente artigo debruça-se com mais detalhe e profundidade nas falas dos alunos desse estudo, especificamente com relação às questões éticas de ordem ambiental e animal. Configura-se como um trabalho necessário dentro desse panorama de empobrecimento de bibliografias e estudos sobre o tema de ética e Bioética na Biologia.

Como referencial teórico para análise dos dados e confeccção das perguntas foi utilizada a Perspectiva dos Funcionamentos, uma corrente ética e de justiça que busca identificar e promover funcionamentos dos diferentes sistemas funcionais (Dias, 2011). Utilizando-se dessa perspectiva podemos encarar os alunos como sistemas funcionais complexos e observar como a formação acadêmica têm promovido ou prejudicado seus funcionamentos.

Através da ótica da Perspectiva dos Funcionamentos podemos também ampliar o escopo de nossos concernidos morais, através do reconhecimento de sistemas funcionais em todos os seres vivos e no próprio ambiente.

Essa amplitude de concernidos morais é mais ampla do que utilizando-se de outras correntes éticas e torna-se relevante quando se pensa na amplitude do trabalho do biólogo, que em suas atuações pode estar diretamente lidando com diferentes formas de vida além de animais sencientes.

O estudo foi realizado dentro de uma instituição de ensino superior federal, com estudantes de Ciências Biológicas do último período através de entrevistas semiestruturadas (anexo I) conduzidas pessoalmente pelo pesquisador. As perguntas variavam de modo a tentar compreender aquele aluno em suas motivações e visões do curso até chegar à identificação de situações éticas que eles vivenciaram e considerassem problemáticas

A escolha por alunos de último período passa pelo maior tempo de vivência acadêmica que possuíam e que permitiram ter uma melhor visão da formação e vivência de situações eticamente relevantes.

As perguntas foram feitas através de entrevistas semiestruturadas (Anexo I). As entrevistas ocorreram pessoalmente, mediante a assinatura do TCLE (Termo de consentimento livre-esclarecido), em uma conversa com o participante. $O$ ideal da pesquisa era exploratório, de identificar questões éticas trazidas pelos próprios alunos de graduação que as vivenciaram ou as pensaram. Um total de 13 alunos, em uma amostra definida pelo método de saturação de respostas (FONTANELLA et al., 2008), foram entrevistados.

O estudo foi devidamente aprovado pelo Comitês de Ética das instituições envolvidas (CAAE 61212516.1.0000.5243). Os participantes tiveram toda e qualquer informação pessoal passível de ser identificável resguardada, de modo a evitar qualquer tipo de ônus pela sua participação. Essa garantia de anonimato inclusive era essencial dentro da pesquisa já que o intuito era explorar que tipo de situações 
problemáticas de cunho ético-moral o aluno tinha vivenciado durante sua formação e isso poderia incluir situações sensíveis e exposição de ações de terceiros.

Cada entrevista foi devidamente gravada e posteriormente transcrita em sua totalidade para análise. Utilizou-se a análise de conteúdo qualitativa com enfoque temático (CAMPOS, 2004). Em uma primeira fase houve uma imersão do pesquisador junto ao corpus adquirido pelas entrevistas e leitura completa. Em uma segunda fase uma leitura mais profunda permitiu uma identificação das respostas dos participantes e agrupamento destas para responder às perguntas da pesquisa. Devido a seu caráter exploratório, as respostas conduziram para mais o encontro de mais questões éticas do que se esperava.

Os fragmentos das entrevistas que serão utilizadas nesse artigo mantêm a forma de falar e palavras utilizadas pelos entrevistados por motivos de máxima fidedignidade. Além disso, anotações foram feitas pelo entrevistador sobre reações dos participantes diante de certas perguntas da entrevista e/ou respostas dadas pelos próprios.

Questões sobre ética animal e ambiental foram trazidas por todos os alunos entrevistados, mesmo que em nenhuma das perguntas feitas a eles houvesse menção explícita sobre questões ambientais e/ou animais. Isso demonstra que questões dentro dessas áreas são recorrentes e passíveis de serem identificadas como problemáticas pelos alunos da graduação

\section{QUESTÃO ANIMAL}

Dentro da questão animalista duas situações foram mencionadas pelos estudantes: o uso de animais como prática didática e o uso de animais em experimentos e estudos.

O depoimento do seguinte entrevistado permite observar melhor a questão do uso de animais em práticas didáticas:

"(Conflito) Ético eu tive com meus professores de Zoo nas aulas de dissecção [....] - E como foi resolvido a questão das aulas? - Não foi, eu fiz a matéria, eu faltei a aula do pombo lá horrível, Zoo 4 e.... sei lá eu me distanciei um pouco, as minhas, os quatro semestres que eu fiz Zoo eu senti que eu tava muito afastada do bem-estar animal porque se eu ficasse conflitando toda vez que eu fosse fazer a pratica eu não ia me formar. E aí eu acabei cedendo porque na minha turma só tinha eu, tinham dois vegetarianos, mas eles não se importavam de abrir animais, então... aí eu abri

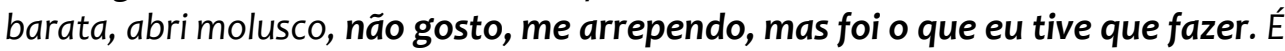
complicado porque você não tem o apoio das pessoas, não tem como." (J.V.)

Nesse fragmento observa-se um conflito direto causado pela estratégia didática adotada pelo professor da disciplina, no caso a dissecção de um animal, e as convicções éticas pessoais da entrevistada. Esse choque acaba por ser danoso para a aluna que se encontra em uma posição de vulnerabilidade em relação ao professor.

Interpelada pelos seus colegas, a aluna confrontou os professores responsáveis pela disciplina e ouviu que não haveria saída para aquela situação e lhe foi negada outra forma de avaliação, restando a ela apenas a opção de realizar a tarefa em clara contradição ao que acredita e pensa. Casos semelhantes foram reportados inclusive dentro da mesma instituição e houve um processo legal realizado por uma estudante para ser dispensada de práticas que envolvessem um animal morto.

O processo legal de número 2009.51.01.009236-foi conduzido pelo reconhecido advogado ambientalista Daniel Lourenço e terminou com um parecer favorável do juiz para sua dispensa e validação de sua Objeção de Consciência através da citação inegável do inciso VIII do art. $5^{\circ}$ da CRFB que diz:

assegura a liberdade de convicção filosófica, não sendo possível, por força desta disposição, que a ré obrigue a autora a participar de tais práticas em oposição a sua convicção filosófica, se ela opta por realizar o respectivo aprendizado anatômico por método alternativo.

Com relação ao uso de animais para fins didáticos há atualmente a Lei Arouca no Brasil, formalmente Lei Ordinária 11.794/2008, que regulamenta o uso de animais para fins didáticos e de 
pesquisa. Segundo ela, tais usos têm de seguir inúmeras diretrizes e cumprir critérios de bem-estar do animal. Sobre o uso em atividades didáticas ela menciona no Artigo 11. $\S 3^{\circ}$ :

Sempre que possível, as práticas de ensino deverão ser fotografadas, filmadas ou gravadas, de forma a permitir sua reprodução para ilustração de práticas futuras, evitando-se a repetição desnecessária de procedimentos didáticos com animais.

Além disso, essa lei regulamentou a criação do Conselho Nacional de Controle de Experimentação Animal, o CONCEA, que auxilia no controle dessas atividades e sua regularização.

A questão da real necessidade do uso de animais em vivissecção e dissecção é posta em xeque na atual realidade, onde há de fato toda uma rica bibliografia que demonstra e apresenta ferramentas didáticas alternativas utilizadas no aprendizado de ensino superior que não envolvam a morte de um indivíduo (SATHYANARAYANA, 2009). Na realidade existem trabalhos que expõem diversas formas de práticas e materiais didáticos alternativos com boas taxas de sucesso relacionado ao aprendizado e avaliação dos alunos e professores (RAVEENDRAN \& BATMANABE, 2011).

De toda forma, existe uma cobertura legal e de incentivo para que os professores tragam formas de avaliação alternativas para os alunos que não quiserem ou se oporem a participar de uma prática que envolva um animal morto. Essa cobertura legal se dá através da Diretriz Brasileira para o Cuidado e a Utilização de Animais em Atividades de Ensino ou de Pesquisa Científica feita pelo CONCEA, que em seu texto inclui o seguinte segmento:

5.1.1. As Instituições que produzem, mantém ou utilizam animais para atividade de ensino ou de pesquisa científica em todo o Território Nacional devem elaborar mecanismos que permitam ao órgão que rege a Instituição ou seu representante garantir sua conformidade com a legislação e com esta Diretriz. Esses mecanismos devem incluir:

(a) disponibilizar metodologias alternativas de avaliação do aprendizado aos alunos que, por escusa de consciência, não participarem de atividades de ensino que envolvam a utilização de animais.

Dessa forma mantêm-se os critérios avaliativos necessários para a disciplina respeitando a decisão ética por parte do aluno em não participar da tarefa.

Observando a situação sob a ótica da Perspectiva dos Funcionamentos, tal objeção por parte do aluno em participar da prática pode ser entendida como uma resposta do aluno, enquanto sistema funcional, de preservar um funcionamento próprio, no caso exemplificado, a capacidade de exercer a liberdade de consciência, negando-se a matar um ser vivo para propósitos educativos. Entende-se aqui que a negação de realizar uma ação é em si uma maneira de agir, portanto a recusa em participar de uma atividade por parte do aluno, em que se implique a morte de um animal como forma de aprendizado, deve ser garantida e assegurada.

Tal situação é vista como problemática até mesmo por alunos que não se sentem pessoalmente do mesmo modo, mas que reconhecem a existência recorrente dessa problematização, como na fala abaixo:

"Ah... bom eu não vejo isso um problema, mas tem pessoa como você falou, tem um problema que acontece aqui na faculdade que você tem que dissecar alguns bichos, você tem que abrir, você tem que fazer. Porque? Porque senão você não consegue terminar supostamente sua faculdade. Porque tá dentro do currículo do que ele está oferecendo e quando você veio assinar aqui, assinar o papel aqui dizendo que você queria ser aluno da UFRJ, você supostamente viu o que aquilo ia te proporcionar, bom enfim, muito diferente da realidade né?" (O.S.)

Em sua fala o aluno invoca um argumento frequentemente utilizado pelos professores ao serem confrontando por alunos sob a real necessidade de utilizar-se de um indivíduo morto para sua aula, o argumento de que uma vez dentro do curso de formação o aluno estaria concordando em participar de 
todos os processos pedagógicos incluídos nela. Esse argumento é derivado de uma visão dos processos didáticos como imutáveis e indica uma resistência a incorporar novas metodologias ou alternativas educacionais que vêm sendo desenvolvidas.

Essa visão explicitada é presente durante a construção do currículo e traz em si todo um arcabouço de conceitos e valores, onde por exemplo, a morte de um animal faz-se não somente irrelevante como também fundamental, apesar de toda a bibliografia crescente afirmar o contrário.

O outro enfoque na questão animal se deu através da experimentação científica em laboratório, como parte de um projeto dentro de um laboratório:

\begin{abstract}
"[...] eu tentei fazer um projeto que era trabalhar com entomotoxicologia e eu pesquisava para ter noção do comitê de ética ne, pra trabalhar com animal e tal porque eu ia usar coelho, e a minha orientadora ela vetou, não me deixou fazer esse trabalho. Mas assim eu fiquei pensando assim, será que eu conseguiria também? Porque eu, com relação ao uso de animais, eu acho que é pelo bem da ciência e tem que ser feito da melhor forma possível, tem que aproveitar o máximo possível daquele animal, mas depois fico pensando pô, mas eu também acho que eu não conseguiria. Eu não sei, acho que ficaria com pena, não sei como seria isso, não cheguei a passar por essa experiência, mas eu mesma fiquei depois pensando poxa eu queria trabalhar com isso, mas eu acho também que eu não conseguiria trabalhar com coelhos entendeu?"( D.L.)
\end{abstract}

Novamente existe um conflito entre o padrão da formação vigente, no caso a experimentação em animais, e a opinião pessoal do entrevistado. Nesse caso, o termo "pena" aparece com central importância, indicando uma ação de cunho afetivo na qual foi construído uma objeção de consciência do entrevistado em realizar a tarefa acadêmica, que no caso citado seria um projeto próprio.

Há um abismo aparente entre um eu pessoal e um eu cientista, o interesse da pessoa com o animal enquanto material de pesquisa, e o interesse da pessoa com o animal enquanto um ser senciente. Ao mesmo tempo que o aluno tem interesse na pesquisa que utiliza o animal, ele tem relutância em utilizarse dessa metodologia por conta do dano causado ao próprio animal.

A esse conflito alia-se uma falta de incentivos do laboratório ou esclarecimentos sobre métodos alternativos para a realização da pesquisa, o que impede muitas vezes o aluno de saber da existência desses métodos e de pensar, portanto na possibilidade de aplicá-Ios (DOKE \& DHAWALE, 2013).

A capacidade de "sentir pena" como descrito pelo entrevistado acima, transmite também uma ideia de cuidado que se tem de ter com o ser à sua frente e foi a expressão mais utilizada pelos alunos dentro da temática da experimentação animal. Outro uso da mesma expressão pode ser ilustrado na fala abaixo:

"É complicado, porque quando a gente pensa num animal que é fofinho aí a gente fica com pena, a gente (pensa) ah poxa tadinho e tal, mas quando a gente vai trabalhar com inseto, ai você pensa ah inseto aí tem que morrer mesmo, as pessoas pensam assim [...] Mas assim, eu acabei me apegando também, a gente acha nojento e tal no primeiro contato, mas a gente acaba se acostumando, claro que não chega a começar a achar que é fofinho também, mas eu acho que acaba por se tornar a mesma relação assim de tentar fazer, usar o animal mas usar, tirar o máximo de proveito possível para que não seja em vão, só fazer um negócio aqui." (D.L.)

Nesta fala do estudante vemos que mesmo o animal longe do fenótipo considerado "bonitinho" ou seja, socialmente atraente ou desejável, fez o aluno nutrir uma sensação que lhe faz sentir-se mal ao utilizá-lo na experimentação. O apegar-se a ele é um sentimento genuíno criado no aluno no contato com o animal, em sua situação de uso, despertando um dos gatilhos de empatia. A empatia quando entendida como uma habilidade de inferir e experienciar o que entendemos ser o sentimento de outros, que podem inclusive ser não humanos, é uma força-motriz de mudanças de paradigmas (PHILLIPS, 2009). Ainda que 
socialmente a ideia seja de repulsa com essa espécie de animal (um artrópode) o aluno pôde sentir pena e relutância em colocá-lo em uma situação que gere sofrimento ou morte.

Estudos como o de Taylor \& Signal (2005) apontam como uma empatia maior por parte das pessoas em relação aos animais converte-se diretamente em ações e interações mais benéficas com eles, não somente com animais de estimação. Portanto, pensar uma educação que fortaleça esse contato e não só permita, mas como incentive o desenvolvimento dessa empatia, em detrimento de sua redução, pode ajudar o biólogo a pensar impactos de sua atuação para seres sencientes e criar profissionais mais comprometidos na construção de um mundo mais igualitário.

Aqui pode-se pensar sobre o desenvolvimento da empatia a partir do conhecimento do outro. A prática da escuta apurada proposta pela Perspectiva dos Funcionamentos maximizada pelos conhecimentos biológicos que temos dos diferentes seres podem propiciar as ferramentas metodológicas cognitivas necessária para identificarmos com maior clareza os funcionamentos de outros sistemas funcionais além dos seres humanos. O reconhecimento desses funcionamentos, em especial os mais básicos, nos permite então traçar estratégias e pensar formas de ação que os leve em consideração.

\section{QUESTÃO AMBIENTAL}

Já a questão ambiental só foi trazida à tona quando perguntado aos estudantes sobre a importância ou visão do biólogo profissional na sociedade. Nesse ponto a questão ambiental, mais especificamente a da preservação ambiental, foi unanimemente mencionada, o que mostra a forte ligação da figura do biólogo à ideia da preservação do ambiente.

De alguma forma, a relação do biólogo com o ambiente torna-se presente na própria visão que se tem dele, tamanha importância tem essa relação no cerne da própria identificação desse profissional. A seguinte fala de um estudante ajuda a ilustrar esse papel do biólogo no imaginário deles:

"[...] falando bem clichê, mas a gente teria meio que agir com um papel de guardião mesmo porque o guardião na mitologia indígena é aquele que sabe e por saber protege. A gente sabe, mas a gente não protege, então..." (J.V.)

Esse entrevistado resgata uma figura mitológica que pode se associar a atuação do biólogo junto a sociedade, o imaginário do guardião. Cria-se um arcabouço mental do biólogo como um salvador, um bastião da defesa da natureza e que vai auxiliar a sociedade a encontrar caminhos para sair dessa crise ambiental, energética e financeira que se instala. Essa mesma imagem sobrecarregada de responsabilidades é assimilada por outros profissionais de outras áreas da Biologia, contribuindo para a criação dessa visão, pelos próprios estudantes de Biologia, durante sua formação, promovendo sua legitimação (ARAÚJO, 2009).

Essa visão permeada de compromissos e deveres é problemática, em virtude da expectativa que se cria em relação ao profissional biólogo como a única referência. Com relação ao receio de recair unicamente sobre a imagem do biólogo a ideia de proteção ao ambiente, o seguinte aluno afirma:

“Conscientização? Só do biólogo? Não, mas é importante também. É do biólogo, é de todo mundo na verdade cara. Depende do que..., da sua área, do que tiver mais perto da sua área, tipo eu gostaria que um economista me ensinasse várias paradas que eu não sei [... ] não é só o biólogo que tem que participar, o biólogo limpa? Não, o biólogo não tem que limpar, o biólogo não tem que jogar lixo lá, ninguém tem que jogar lixo. Não é só o biólogo, é todo mundo, vamos limpar, não vamos jogar nada, mas tem que conscientizar. Mas não é só dever do biólogo, não é só do biólogo, é dos políticos aí, todo mundo, até porque não é só o biólogo, tem também a saúde pública, e a saúde pública é só o biólogo? Não, eu não me lembro disso." (C.M.)

Analisando essa fala, podemos perceber que a questão da conscientização é um dever e ação coletiva, envolvendo profissionais de diversas áreas e a sociedade em seu total. Com essa divisão de 
responsabilidades fica mais fácil pensar uma ação global de alcance amplo e maior efetividade.

Ao mesmo tempo que se percebe que não deve recair unicamente sobre o biólogo a esperança definitiva de construir ações de mudanças de paradigmas na questão ambiental, sob ele há sim uma expectativa de que possa, através de seu expertise e formação específica, conduzir e demonstrar às pessoas caminhos de preservação e conservação do ambiente.

Em suma como bem discorre um entrevistado, cabe ao biólogo um papel de influenciar e transformar:

"Eu acho que o principal do biólogo é poder influenciar, ser um agente transformador, porque a gente aprende várias coisas e a importância do meio pro nosso trabalho, então a gente consegue influenciar as pessoas nesse termo, seja trabalhando lá na analítica até na ecologia, você ser um agente influenciador das outras pessoas, acho que ser biólogo faz você mudar o pensamento das pessoas ao seu redor" (C.B.)

O perfil profissional do biólogo modificou-se ao longo dos tempos, derivando da imagem tradicional de um acadêmico isolado do resto da população junto a suas teorias para agora um agente influenciador, como disse o entrevistado, da própria sociedade, sendo efetivo numa transformação social com base em sua expertise e reflexões (DESTEPHANO \& STEILD, 2000).

Um dos termos mais mencionado pelos estudantes frente a essa temática ambiental foi justamente o de sustentabilidade, como exemplificado na fala a seguir:

"De novo a questão principalmente ambiental, eu sempre caio para esse lado do ambiental, [...] acho que a importância do biólogo é justamente tentar guiar um tipo de vida mais sustentável, conseguir guiar o desenvolvimento..." (R.F.).

Após levantar essa importância do biólogo como guia para alcançar a sustentabilidade, o aluno explorou mais sobre o conceito:

"Tem diversos meios de você conseguir atingir alguma coisa, mas tentando minimizar os danos sabe? Se é uma questão de gasto de energia, ou uma questão de reciclagem, tipo água empoçada que podia ser tratada, reciclagem de lixo, papel, tudo isso acho que são coisas que a gente faz, meio que deixando pra lá e que pode ser tratado e reutilizado e facilitaria bastante." (R.F.)

A sustentabilidade surge como conceito em meados de 1987 através da ONU, com a seguinte definição: "desenvolvimento que compreende a necessidade dos presentes sem comprometer a habilidade de gerações futuras de satisfazer suas próprias necessidades." (ONU, 1987).

O termo "desenvolvimento sustentável" envolve um conjunto de métodos para manter a produtividade, reduzindo o impacto da produção econômica com o ambiente. É bem perceptivel, entretanto, o tom antropocêntrico nessa definição atualizada, que o termo sustentabilidade carrega. A importância que se dá ao ambiente ainda é principalmente instrumental, como forma de manter a sobrevivencia de futuras gerações, que no caso seriam os seres humanos e o progresso econômico existente. Importante ressaltar também que não se englobaria todos os seres humanos nesse conceito de toda forma, já que o processo produtivo atual, fruto desse progresso econômico vigente que se procura manter, por vezes sacrifica vidas de determinados seres humanos para seu desenvolvimento.

Esse conceito foi ampliado em posteriores reuniões, em 2012, para incluir as esferas do desenvolvimento econômico, da preservação de recursos, da saúde humana e da preservação das espécies (ONU, 2012). O termo foi amplamente adotado pelas empresas e mídia, rapidamente caindo no conhecimento coletivo e sendo objeto de demandas tanto do mercado quanto dos consumidores (HART, 2013). Com isso aumenta a importância do biólogo, o profissional cientista que melhor estuda as relações ambientais, como enfatiza o entrevistado abaixo:

"Isso acontece muito no jornal né, ah cientistas dizem que isso é isso, você gera uma comoção na sociedade, ah se os cientistas estão dizendo isso eles estão certos, ou 
eles estão mais próximos de estar certo, a gente acaba tendo uma confiança meio cega né, e isso gera, se um biólogo disse que coletou lá, fez estudo e viu que não tem, as espécies que tem lá se elas não deixarem de estar lá não vai ter impacto, então tá okay eu desmatar e sei lá pra que fazer. "(J.P.)

A fala ilustra a confiança que a população tem em um profissional biólogo, capacitado para lidar com questões do ambiente, e a responsabilidade que este deve ter com o seu trabalho. $O$ estudante atenta em sua fala que uma ação mal realizada ou uma má-conduta por parte do biólogo profissional pode gerar impactos ambientais severos e gerar consequências irremediáveis para os seres vivos da área.

Como medida preventora de tais atitudes uma medida importante seria a inclusão de reflexões éticas ou simplesmente espaços de reflexão e diálogo sobre a própria atuação do biólogo, que o curso deveria ser o promotor, algo que não tem ocorrido segundo os próprios alunos:

"[...] sempre tinha uma discussão voltada (ética), mas sempre pro meio acadêmico. Falando a verdade os debates sempre giravam nesse ponto, na atuação do biólogo de verdade eu nunca participei. Eu ainda acho que isso faz falta, isso é muito importante." (C.B.)

Sem a inclusão de espaços destinados a reflexões, ou mesmo disciplinas que incentivem esse tipo de debate, os alunos formam-se com um enfoque tecnicista e produtivista, em especial dentro do meio acadêmico, diante do processo nomeado Publish or Perish que conecta a valorização do professorpesquisador à sua produtividade científica (VILAÇA \& PALMA (2013)

\section{CONCLUSÃO}

É impossível reavaliar os presentes conceitos e divisões apresentados dentro do currículo atual de Ciências Biológicas sem levar em consideração os valores ou ideais presentes por detrás deles. Um currículo vigente antes de tudo é uma construção cultural e com isso transmite em seus conteúdos e práticas didáticas concepções impostas por grupos dominantes (OLIVEIRA, MELO \& VERÍSSIMO, 2016).

Através dessa construção de cultura social hegemônica pode-se calar vozes dissonantes ao projeto de desenvolvimento político-econômico e assegurar seu sucesso. Frequentemente essas vozes são silenciadas através de uma violência curricular, que descarta e desmerece conteúdos e disciplinas que não se alinhem a essa estrutura de poder e pensamento (GIOVEDI, 2013). Tal poderia ser o caso da não inclusão de Bioética ou ética em muitas instituições de ensino superior.

Portanto, refletir sobre um currículo é também refletir sobre o contexto sócio-político e cultural onde aquele curso e instituição estão inseridos. Trago aqui a noção do currículo oculto, entendido como um conjunto de valores e comportamentos que não estão explícitos dentro do currículo formal, mas de toda forma estão vividamente presentes dentro das instituições de ensino, através de suas práticas, rituais e relações sociais (SILVA, 2000).

Explicitar esses valores que permeiam e motivam a construção dessa forma de ensinar é o primeiro passo para desconstruí-los e evitar que a academia se torne mera reprodutora de padrões de opressão e violência.

Estudos demonstraram a existência e o impacto do machismo e racismo dentro da academia (TEIXEIRA, 2011; BORING, OTTOBONI \& STARK, 2016; GRUNSPAN et al. 2016), bem como o do especismo (TRÉZ \& NAKADA, 2008). Essas formas de visões violentas podem ser entendidas em conjunto e não isoladamente, em um esquema de violência interseccional que gera múltiplas opressões e é fruto de uma forma de pensar hegemônica que prioriza um determinado grupo social em detrimento de todos os outros.

Através deste estudo buscamos trazer as vozes, por vezes silenciadas, dos alunos com relação às suas questões de cunho ético-moral que não estão sendo devidamente trabalhadas dentro de sua formação. A não-existência de espaços para reflexão ou livre debate sobre a própria atuação do biólogo, 
bem como um déficit sobre a ética profissional ou Bioética (em especial dentro das áreas de ética animal e ambiental) é um dado extremamente relevante.

Podemos perceber nas falas dos alunos conflitos, dilemas, preocupações éticas que foram geradas durante sua formação e vivência acadêmica. Longe de serem abarcadas pelo curso, foram geradas pelo mesmo e formam angústias nesses recém-formados profissionais.

Similarmente o estudo buscou trazer entre as vozes silenciadas na construção desse currículo as vozes dos animais enquanto material de pesquisa ou didático. O pouco interesse apresentado pelos professores em mudar essa situação aliada ao desconforto apresentados pelos estudantes quando confrontados por tais situações demonstram uma resistência à adoção ou simples reconhecimento de outras formas de produzir conhecimento que não envolvam a morte ou crueldade com um ser senciente.

Um profissional que está na linha de frente na sociedade de variadas questões polêmicas e eticamente relevantes, tais como preservação ambiental levantamento de fauna/flora, experimentos científicos e educação básica e superior, e que amplamente lida com dilemas e problemáticas de cunho ético-moral, não possuir qualquer disciplina que aborde ética em sua formação é no mínimo irresponsável.

Um profissional como o biólogo, que possui tanto na visão popular quanto corroborado pelos próprios alunos, uma expectativa alta com relação a lidar com questões ambientais não possuir uma reflexão ética-moral sobre tais questões ou da natureza de sua própria atuação é insatisfatório se pensarmos no profissional que queremos atualmente. Não só um especialista técnico na sua área, mas um agente efetivo de mudanças sociais, consciente do contexto cultural e político onde estão inseridos e dotados de ferramentas para enfrentar quaisquer questões de sua atuação.

Acreditamos que a instauração de espaços para dar voz às essas demandas e questões dos alunos em formação, e especialmente para incentivo a reflexão, pode ser um caminho para se pensar uma educação que maximiza os funcionamentos de seus alunos. Como sistemas funcionais complexos seus funcionamentos são variados e individualmente distintos, e devem ser considerados e ouvidos na medida em que se constrói um currículo e que se pretenda uma educação construtiva.

O resgate da Bioética no contexto da Biologia parece ser um caminho para suprir demandas dos próprios estudantes pelo desenvolvimento e exercício de determinados funcionamentos ou capacidades necessárias à sua formação e atuação futura como profissionais, trazendo um espaço de reflexão à essa formação técnica. Essa inserção pode-se dar através de uma disciplina pontual, ou como um conceito transdisciplinar, aproveitando-se da sua natureza intrinsicamente multidisciplinar. Ocorreria a semelhança de como, por exemplo, a Biossegurança, também em si uma área multidisciplinar, é trabalhada em outros cursos (COSTA \& COSTA, 2013). Portanto, temas relativos a Bioética e a Ética dentro da Biologia seriam mencionadas e abordadas por diferentes professores em diferentes disciplinas.

Essa forma de abordagem enriquece a visão da Bioética dentro do curso, já que professores de diferentes especializações provavelmente reconheceriam diferentes situações como eticamente problemáticas, e também aprofundariam os debates. Isso por sua vez permite ao aluno uma visão ampla das possíveis situações éticas que o biólogo pode encontrar em suas atuações e especializações.

Mais do que somente reestruturar o currículo é também uma questão de se repensar a forma de como se faz ciência no Brasil. Uma ciência que ainda se baseia em conceitos antiquados e que não incorpora avanços em metodologias alternativas corre sério risco de repetir padrões de opressão e exploração calcados na própria raiz de uma forma de pensar antropocêntrica.

Por fim alinhado ao pensamento de Freire (1987) pensamos uma educação libertadora que consiga alinhar conteúdos pragmáticos com um ensino que proponha um espírito crítico e reflexivo, com participação do educando no processo educacional, de modo a romper com a reprodução de ciclos de violência e opressão. Uma formação que não atenda aos conflitos trazidos pelos estudantes e que em sua origem gere esses mesmos conflitos torna-se uma formação deficitária. Tal formação pode colocar em xeque que tipo de profissionais se está tentando formar. 
Para tanto, resgato as palavras de Van Rensselaer Potter, bioquímico comumente reconhecido por ter sido o primeiro a usar o termo Bioética, em seu livro "Bioética: Ponte para o futuro", sobre a necessidade da criação de uma ponte entre valores "humanos" e o conhecimento científico teórico crescente:

Eu tomo a posição que a ciência da sobrevivência deve ser construída sobre a ciência da Biologia e expandida além das fronteiras tradicionais afim de incluir os elementos mais fundamentais das ciências sociais e humanas, com enfoque na filosofia no sentido estrito, ou seja "amor a sabedoria". Uma ciência da sobrevivência deve ser mais do que uma ciência sozinha, portanto eu proponho o termo Bioética para enfatizar os dois ingredientes mais importantes na obtenção dessa nova sabedoria tão desesperadamente necessária: conhecimento biológico e valores humanos.

O espaço atual da universidade contribui para uma formação técnica e especializada do biólogo profissional, com uma visão majoritariamente tecnicista. Em contrapartida ela pouco contribui para uma formação moral e crítica do biólogo, o que o capacitaria para lidar com as atuais demandas do mundo real. Mais do que somente uma referência técnica e científica, é exigido do biólogo um posicionamento ético frente especialmente a questões ambientais e animais. Atender essas demandas, acusadas pelos próprios alunos de Biologia é um caminho efetivo para o preparo de profissionais aptos a construir uma sociedade mais igualitária.

\section{REFERÊNCIAS}

ARAUJO, Guilherme Augusto de Domenico. Os papéis do biólogo: Reflexões sobre o imaginário da profissão biólogo. 43p. Monografia (Graduação em Ciências Biológicas) - Curso de Ciências Biológicas, Universidade Federal de Santa Catarina, Florianópolis, 2009.

AZEVEDO, Maria Alice da Silva. Origens da Bioética. Nascer e Crescer, v.19, n.4, p. 255 - 259, 2010.

BORING, Anne; OTTOBONI, Kellie; STARK, Phillip. 2016. Student evaluations of teaching (mostly) do not measure teaching effectiveness. Science Open Research

BRYANT, John; LA VELLE, Linda Baggott. A bioethics course for biology and science education students. Journal of Biological Education, Nova lorque, v.37, n. 2, p. 91-95, 2003.

CAMPOS, Claudinei José Gomes. Método de análise de conteúdo: ferramenta para a análise de dados qualitativos no campo da saúde. Revista Brasileira de Enfermagem, Brasília, v.57, n. 5, p. 611 - 614, 2004.

CARNEIRO, Larissa Arbués; PORTO, Celmo Celeno; DUARTE, Soraya Bianca Reis; CHAVEIRO, Neuma; BARBOSA, Maria Alves. O ensino da ética nos curso de graduação da área da saúde. Revista Brasileira de Educação Médica, Brasília, v. 34, n. 3, p. 412 - 421, 2010.

CONRADO, Dália Melissa; EL-HANI, Charbel Nino; NUNES-NETO, Nei de Freitas. Sobre a ética ambiental na formação do biólogo. REMEA - Revista Eletrônica do Mestrado de Educação Ambiental, Rio Grande, v.30, n.1: p. 120-139, 2013.

COSTA, Marco Antonio Ferreira; COSTA, Maria de Fátima Barrozo. Biossegurança em saúde no ensino de ciências. Revista Práxis, Volta Redonda, v. 9, p.11 - 15, 2013.

DeSTEFANO, Stephen \& STEIDL, Robert. The professional biologist and advocacy: What role do we play? Human Dimensions of Wildlife, v.6, n.1, p. 11-19, 2000.

DIAS, Maria Clara (Org.) A Perspectiva dos Funcionamentos: Por uma abordagem moral mais inclusiva. Rio de Janeiro: Pirilampo, 2015. 228p.

DOKE, Sonali; DHAWALE, Shashikant. Alternatives to animal testing: A review. Saudi Pharmaceutical Journal,Riad, v.23, p. 223-229, 2015. 
DOWNIE, Roger. The teaching of bioethics in the higher education of biologists. Journal of Biological Education, v. 27, n.1, p. 34-38, 1993.

FONTANELLA, Bruno José Barcellos; RICAS Janete; TURATO, Egberto.Ribeiro. Amostragem por saturação em pesquisas qualitativas em saúde: contribuições teóricas. Caderno de Saúde Pública, Rio de Janeiro, v.24, n.1, p. 17-27

FREIRE, Paulo. Pedagogia do Oprimido. $17^{\mathrm{a}}$ ed., Rio de Janeiro: Paz e Terra, 1987. 256p.

GIOVEDI, Valter Martins. Violência curricular na escola pública: Conceito e manifestações. Revista Teias, v. 14, n. 33, p.121-137, 2013.

GRUNSPAN, Daniel; EDDY Sarah; BROWNELL, Sara; WIGGINS, Benjamim; CROWE, Allison; GOODREAU, Stephen. Males Under-Estimate Academic Performance of Their Female Peers in Undergraduate Biology Classrooms. Plos ONE, v.11, n.2, doi:10.1371/journalpone.0148405, 2016.

HART, Stuart. A riqueza na pobreza. Revista Ídeia Sustentável. Disponível em: http://www.ideiasustentavel.com.br/2013/02/entrevista-stuart-hart. Acesso em: 15 de Setembro de 2018.

KOLAROVA, Teodora Aleksandrova; DENEV, Ilya Dimitrov. Integrating a Bioethics Course Into Undergraduate Biology Education. Biotechnology \& Biotechnological Equipment, Nova lorque, v.26, n.1, p. $2801-2810,2012$.

KOHLBERG, Elizabeth. A Sexta Extinção - Uma História Não Natural. Rio de Janeiro: Intrínseca, 2015. 336p.

LOPES, Lucas Nascimento Ferreira. Bioética e Biologia: Visões e questões éticas dos estudantes de Graduação. 112p. Dissertação (Mestrado em Bioética, Ética Aplicada e Saúde Coletiva) - PPGBIOS, Universidade Federal Fluminense, Rio de Janeiro, 2017.

MELO, Fabíola Cristina; OLIVEIRA, Maria Betânia Pereira; VERÍSSIMO, Melina Teixeira da Costa. Quais são as vozes do currículo oculto? Evidência, Araxá, v. 12, n. 12, p. 195-203, 2016

PESSINI, Leo. As origens da bioética: do credo bioético de Potter ao imperativo bioético de Fritz Jahr. Revista Bioética, Brasília, v.21, n.1, p. 9-19, 2013.

PHILLIPS, Clive. The welfare of animals: the silent majority. Amsterdam: Springer, 2009. 220 p.

PINTO, Gabriela Bertti da Rocha. A ausência da ética animal nas disciplinas de Bioética nos currículos do curso de Ciências Biológicas no Brasil. 94p. Dissertação (Mestrado em Bioética, Ética Aplicada e Saúde Coletiva) - PPGBIOS, Universidade Federal Fluminense, Niterói, 2016.

POTTER, Van Rensselaer. Bioética: Ponte para o futuro. São Paulo: Loyola, 2016. 208p.

ONU.O Futuro que queremos - Declaração final da Conferência das Nações Unidas sobre Desenvolvimento Sustentável. 2012. Disponível em <http://www.mma.gov.br/port/conama/processos/61AA3835/O-Futuroque-queremos1.pdf> . Acesso em 15 de Setembro de 2018.

RAVEENDRAN Ramasamy; BATMANABE Gitanjali. Alternatives to animals in teaching: Experience in an Indian medical school. Proceedings of the ALTEX 8th World Congress, Montreal, v.1, n.12, p. 355-360, 2011.

SAPP, Jan. Genesis: The Evolution of Biology. Oxford: Oxford University Press, 2003. 364p.

SATHYANARAYANA, Mukkura. Need for Alternatives for Animals in Education and Alternative Resources. Procedings of Animal Alternatives in Teaching, Toxicity, Testing and Medicine, v.1, n.13, p. 77 - 81, 2009.

SIEBERT, Paloma Rodrigues. Bioética para Estudantes de Ciências Biológicas: Investigação sobre os Fundamentos que Compõem ou Deveriam Compor a Área. 157 p. Tese (Doutorado em Educação para a Ciência) - Programa de Pós-Graduação em Educação para a Ciência, Universidade Estadual Paulista, São Paulo, 2015

SILVA, Tomaz Tadeu. Teoria cultural e educação: um vocabulário crítico. Belo Horizonte: Autêntica, 2000. 127p.

SILVA, Paulo Fraga. Educação em Bioética: desafios na formação de professores. Revista Bioética, v.19, n.1, p. $231-45,2011$. 
ISSN $1983-1579$

Doi: 10.22478/ufpb.1983-1579.2018v3n11.41992

http://periodicos.ufpb.br/ojs2/index.php

TAYLOR, Nik.; SIGNAL, Tania. Empathy and atitudes to animals. Anthrozoös. v.18, n.1, p. 18 - 27, 2005.

TEIXEIRA, Michelle Cecille Bandeira; DIAS, Maria Clara; RIBEIRO, Carlos Dimas Martins. A perspectiva dos funcionamentos para a educação superior em saúde, p. 155-178. In: DIAS, Maria Clara (org). A Perspectiva dos Funcionamentos. Rio de Janeiro: Pirilampo, 2015. 228p.

TRÉZ, Thales; NAKADA, Juliana Isabel Lopes. Percepções acerca da experimentação animal como um indicador do paradigma antropocêntrico-especista entre professores e estudantes de Ciências Biológicas da UNIFAL-MG. Revista de Educação em Ciência e Tecnologia, v.1, n.3, p. 3- 28, 2008.

VILAÇA, Murilo.Mariano; PALMA, Alexandre. Diálogo sobre cientometria, mal-estar na academia e a polêmica do produtivismo. Revista Brasileira de Educação, v.18, n.53, p.467 - 50, 2013. 


\section{Anexo I - Roteiro das Pergunta para Entrevista Semiestruturada \\ Perguntas Base das Entrevistas}

- O que lhe levou à Biologia?

- O que lhe levou à essa atuação específica?

- Quais são as atuações do Biólogo para você? Onde você o vê atuando na sociedade? Identifica algum conflito nessa atuação?

- Já vivenciou algum conflito durante sua formação, conflito ético, pessoal, moral que a Biologia tenha proporcionado?

- Você teve espaço para reflexão dentro da sua formação?

- Quais as especializações em Biologia que você identifica que existe? Acha importante ter essas divisões?

- Como você lida com conflitos pessoais seus?

- O que é Ética para você?

- Você acha que a Ética é importante para um biólogo? Como? E dentro do seu trabalho?

- Qual a importância do Biólogo na sociedade? Ele é importante?

- Você acha que o Biólogo é valorizado dentro da sociedade? 